\section{THE REASON FOR THE HISSING OF THE ELECTRIC ARC.}

H ISSING is one of the few phenomena connected with the electric arc with which every one is more or less familiar. In the old days the sudden, almost complete, extinction of the light of an arc-lamp, and the loud hiss accompanying its relighting, was so common an occurrence that it was supposed by the lay mind to form part and parcel of the working of the "electric light," and led to a lively prejudice against that light on the part of the public. In these days of enclosed arcs and of better constructed lamps, such little interludes are of far less frequent occurrence; but it is as important as ever, from a scientific point of view, to discover their origin, and even from the practical side anything which points to a remedy for this grave defect in arc-lighting cannot fail to be of interest.

The object of the present article is to explain the cause of hissing in direct current open arcs; that is to say, in arcs in which the current flows always in one direction, and to which the air has free access at every point. a sound something like that of steam under pressure, issuing from a pipe. This sound is accompanied by a diminution of about ten volts in the P.D., or electric pressure between the carbons, and an increase in the current.

For the experiments on which the present article was based, three sets of electrical measurements were made, viz. measurements of the current, the P.D. between the carbons, and the length of the arc. Before each observation was made the current and length of arc were kept rigorously constant for a sufficient length of time for the carbons to take their characteristic shape for that particular current and length of arc, and long enough, therefore, for the P.D. to have become constant also. Such an arc is called a normal arc, as contrasted with one arrived at in a haphazard fashion by suddenly giving the current some particular value and the arc some particular length, and making observations without allowing time for the carbons to acquire their proper forms.

The carbons used were generally both solid, that is, neither had a soft core such as is usually given to the positive carbon when the arc is employed for lighting purposes, and they were,

OPEN ARCS.

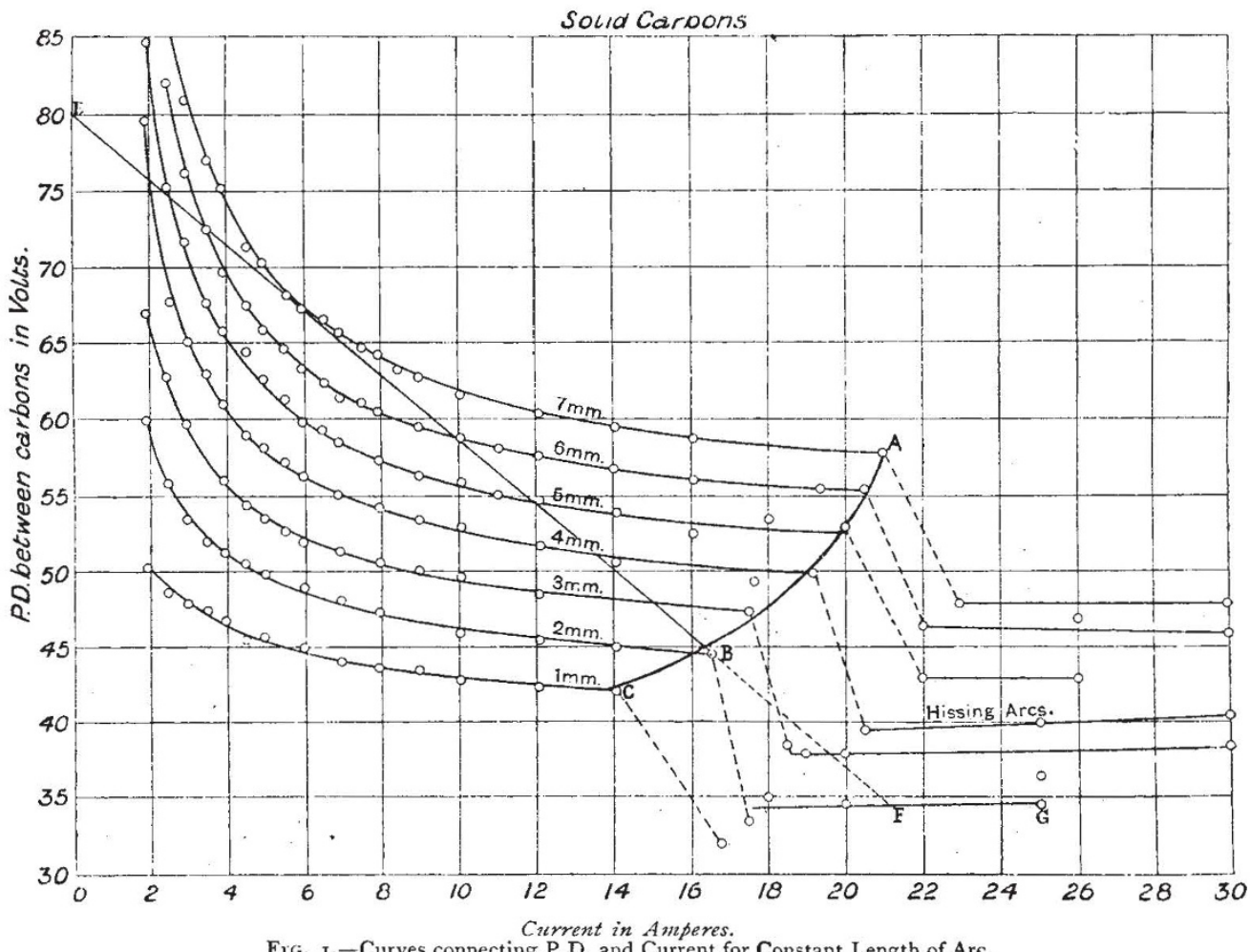

FrG. I.-Curves connecting P.D. and Current for Constant Length of Are.

Carbons :-Positive, Ir mm. ; Negative, $9 \mathrm{~mm}$.

There are other ways in which a change taking place in the arc may manifest itself, in addition to giving out sounds of various kinds or by becoming silent. For example, there may be changes in its electrical measurements, or an alteration in the appearance of the crater, the arc, and the carbons.

The sounds given out by the direct current open arc are many and various, but only two seem to possess much significancethe hum and the hiss-and the causes of these are evidently connected with one another, for the hum never occurs except when the arc is on the point of hissing or has just been hissing, although it is quite possible to make an arc hiss and become silent again without any hum being heard either before or after.

The hum is a distinct musical note, which is often quite low to start with, and gets higher and higher, till it finally rises to a shriek, and then the arc breaks into a loud hiss, giving forth 1 Based on a paper read before the Institution of Electrical Engineers by Mrs. W. E. Ayrton.

N. I 55 I, VOL. 6o] as usual, placed vertically over one another with the positive carbon on top.

Some of the results of these experiments are given in Fig. I, in which the curves connect the P.D. between the carbons with the current, for various constant lengths of arc. Starting from the left, each curve goes smoothly on its way, as the current increases, till a certain point is reached, when it suddenly breaks down, and is continued in a straight line far below and to the right of its own lowest point. The break-down occurs when the current has such a value that the arc can no longer remain silent. The dotted lines, which join the curves for silent arcs to the straight lines for hissing arcs of the same length, indicate ranges of current that will not flow through the particular length of arc indicated at all if the are is normal with the arrangement of the circuit existing when the experiments were made.

An examination of these curves shows that with the carbons used, and with the normal arc, the following results are met with 
(I) When the length of the arc is constant and the arc is silent, it may be made to hiss by increasing the current sufficiently.
(5) For the hissing arc the P.D. is constant for a given length of arc, whatever the current.

It was Niaudet (La Lamiere Electrique, 188 r, vol. iii. p. 287)

OPEN ARCS.

Positive Carbon Cored.

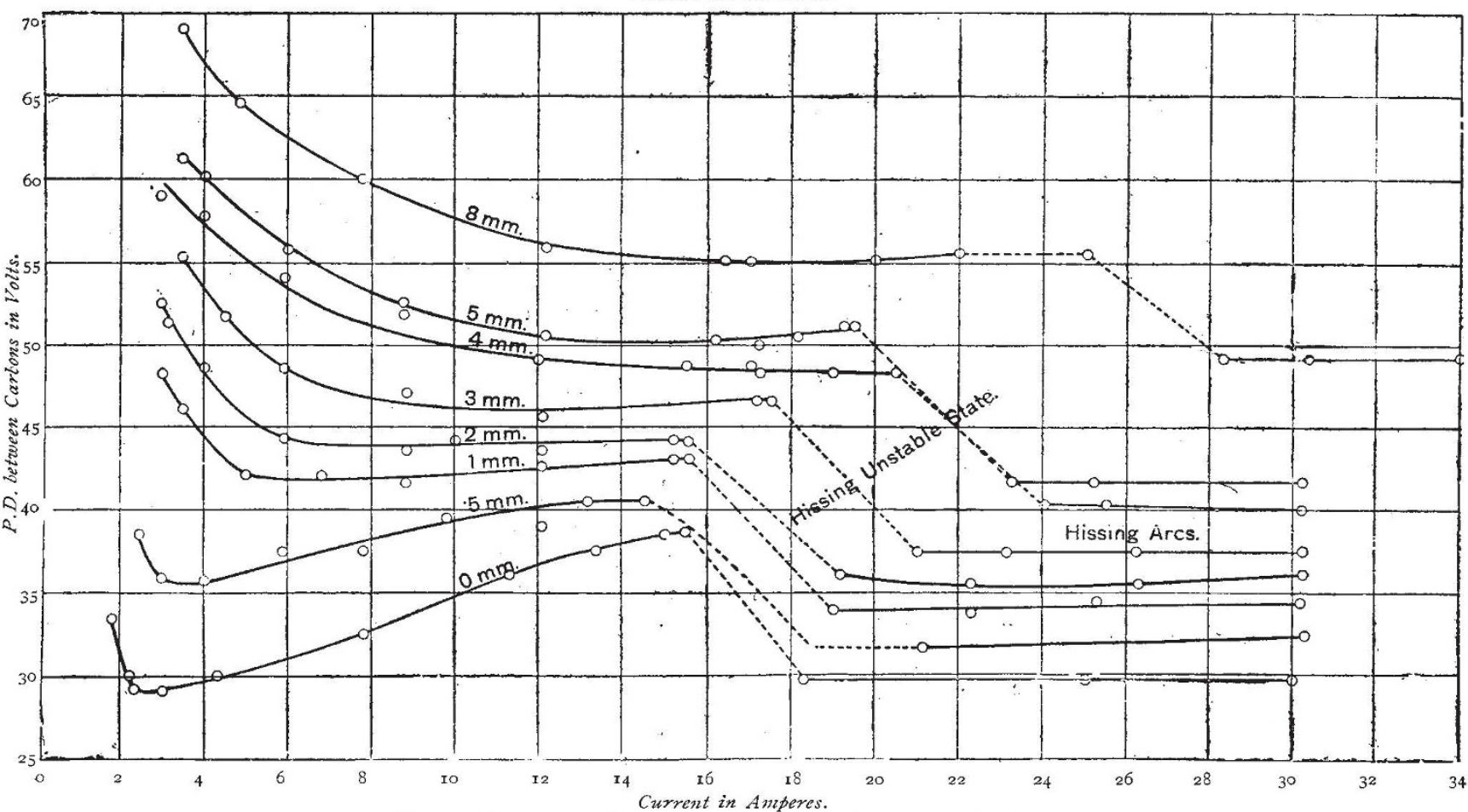

FIG. 2.-Curves connecting P.D. and Current for Constant Lengths of Arc.

Carbons :-Positive, $9 \mathrm{~mm}$. Cored.; Negative, $8 \mathrm{~mm}$. Solid.

(2) When the current is constant and the arc is silent, | who, in $188 \mathrm{I}$, first observed the fall of about 10 volts in the shortening the arc will make it hiss.

(3) The largest current that will maintain a silent arc is P.D. between the carbons at the moment hissing began, and, greater the longer the arc. although perhaps there is even yet a lingering notion that it is
only when an arc is short that it can hiss, I find that as far back

OPEN ARCS.

Positive Carbon Cored.

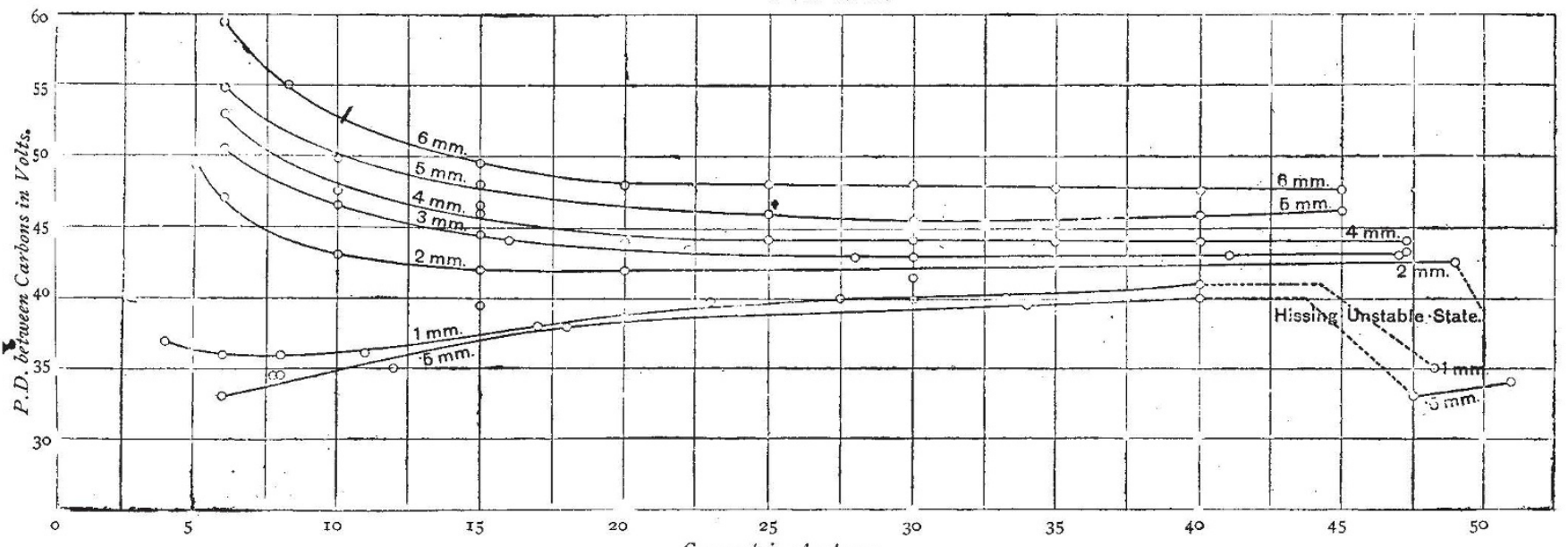

Fig. 3-- Curves connecting P.D and Current for Constant Lengths of Arc Carbons :--Positive, $18 \mathrm{~mm}$. Cored. ; Negative, $15 \mathrm{~mm}$. Solid.

(4) When the arc begins to hiss, the P.D. suddenly falls about Io volts and the current suddenly rises two or three amperes.

NO. I 55 I, VOL. 6o] as 1889 Luggin (Wien Sitzungsberichte, 1889, vol, xlvii. p. I I8) showed that, however long an arc might be, it would still hiss were the current increased sufficiently. 
At the Congress at Chicago in 1893 Prof. Ayrton (The Electracian, 1895, vol. xxxiv. pp. 336-7) first drew attention to the region of instability indicated by the dotted portions of the curves. At the same time he pointed out in Fig. 2, shown at Chicago, that whether the P.D. was descending as the current increased for, say, a $4 \mathrm{~mm}$. arc, or was ascending for, say, a 0.5 $\mathrm{mm}$. arc, it became quite constant for wide variations of current with a hissing arc

And, lastly, by a comparison of Fig. 2 with Fig. 3 he brought out the fact that the largest current that would flow silently with any given length of arc was increased by using thicker carbons; for the carbons in Fig. 3 have about twice the diameter of those in Fig. 2, and while the largest silent current for, say, the $2 \mathrm{~mm}$. arc in Fig. 2 is 15.5 amperes, that for the same length of arc in Fig. 3 is about 49 amperes, or more than three times as great.

Returning now to the subject of the dotted lines in Figs. I, 2 and 3 , it is plain that these divide the curves into two perfectly separate parts, governed by different laws. For to the left of the dotted part the lines are all curved, and curved differently according as solid positive carbons are used as in Fig. I, or cored as in Figs. 2 and 3, showing that with silent arcs the P.D. varies as the current varies, and that the law of variation is different with solid and cored carbons. To the right, on the other hand, the lines are all straight, and more or less parallel to the axis of current, whether the positive carbon is solid or cored, showing that with hissing arcs the P.D. is the same for a given length of arc and a given pair of carbons, whatever current is flowing, and that this law is true whether the carbons be cored or solid. In fact, when the arc begins to hiss some complete and sudden break.down appears to occur, upsetting all the laws that have governed it while it was silent, and making cored and solid carbons behave alike.

Thus, our subject divides itself quite naturally into two distinct portions, the one dealing with the arc when the breakdown is imminent, but before it has actually occurred-dealing, that is to say, with the points at which the current is the largest that will flow silently-the hissing points as I shall call them; and the other dealing with the arc after the break-down has occurred, and when, therefore, the arc is really hissing.

An examination of Fig. I shows that the hissing points lie well on the curve A B C; that curve may, therefore, be taken to embody the laws connecting the P.D. between the carbons, the current, and the length of the arc, at the hissing points, for at least all those lengths of arc given by the curves in Fig. $x$. The most important of these laws concerns the current at the hissing point, the largest silent current.

It is quite plain, from Fig. I, that although this current in creases as the length of the arc increases, yet it does not increase at the same rate as the length of the arc. For each millimetre added to the length of the arc involves a smaller and smaller addition to the largest silent current; so that finally a current must be reached which will not increase appreciably however much the arc is lengthened, always supposing that the law continues to hold for such long arcs. Hence, on this sup. position, for each pair of carbons the current that will sustain a normal silent arc has a maximum value, and any current greater than this will make the arc hiss, however long it may be.

Other laws concerning the arc when on the point of hissing and when actually hissing can be deduced directly from Figs. I, 2 and 3 , but as these do not bear directly on the cause of hissing, the mathematical proofs of them may with advantage be omitted from the present article. Some of these laws may, however, be summed up as follows :-

If $\mathrm{V}$ be the P.D. in volts between the carbons at the hissing point for an arc of $l$ millimetres, and if $V^{\prime}$ be the constant P.D. between the carbons for a hissing arc of the same length, then

and consequently

$$
\begin{aligned}
& \mathrm{V}=40 \cdot 05+2 \cdot 49 l, \\
& \mathrm{~V}^{\prime}=29 \cdot 25+2 \cdot 75 l,
\end{aligned}
$$

$$
\mathrm{V}-\mathrm{V}^{\prime}=10.8-0.26 l \text {, }
$$

which shows that the longer the alc the less is the P.D. between the carbons diminished when it changes from silence to hissing.

The numerical coefficients in the above equations naturally refer only to the carbons I used in my experiments, but the laws expressed by the equations must be true for all direct current open arcs of lengths not differing very greatly from those I used, and burning between solid carbons.

No. 1551 , vOI. 60 ]
From Fig. I it might be supposed that, given the length of the arc, the increase of current that abruptly occurs on the arc starting hissing was as definite for that length of arc as the diminution in the P.D. And this, for a long time, I imagined to be the case. But while trying to find out what law connected the smallest hissing current with the length of the arc, I saw that the value of that current really dependecl on the circuit outside the arc. I found, in fact, that when the largest silent current for any length of arc changes to the smallest hissing current for the same length of arc, the value of that smallest hissing current depends on the E.M.F. of the dynamo only'. The smaller that E.M.F. is, the greater will be the smallest hissing current for any given length of arc, while if the E.M.F. of the dynamo could be made infinite, the smallest hissing current and the largest silent current would be equal; that is to say, when the arc began to hiss the Y.D. between the carbons would drop, but the current would remain quite unchanged.

Thus it is possible, by choosing suitable E.M.F.s, to make the sudden smallest hissing current have any value greater than that of the largest silent current for the same length of arc.

In 1889 Luggin found, by measuring the fall of potential between each carbon and the arc, that the principal part of the diminution of P.D. caused by hissing took place at the junction of the positive carbon and the arc. Some experiments of the same sort that I made about three years ago, using arcs varying between $1 \mathrm{~mm}$. and $6 \mathrm{~mm}$, gave the same result.

For the lengths of arc dealt with, I found that hissing caused a mean fall of about 9.7 volts in the total P.D. between the carbons, and a mean fall of about 6.3 volts in the P.D. between the positive carbon and the arc. Hence of the whole diminution of the P.D. between the carbons caused by hissing, about twothirds took place at the junction of the positive carbon and the arc.

Further, my experiments showed that very little of the re. mainder of the diminution, if any, was due to a diminished fall in the P.D. between the arc and the negative carbon; therefore this remaining diminution must be attributed to a lowering of the resistance of the arc itself. We may sum up these results as follows :-

Of the total diminution of the P.D. between the carbons caused by hissing, about two-third's takes place at the junction of the postive carbon and the arc, and the remaining third seems to be due to a lowering of the resistance of the arc itself.

We now pass from the consideration of the electrical measurements of the arc to the appearance of the crater, arc, and carbons.

Every alteration of the current and of the distance between the carbons naturally produces a corresponding modification of all parts of the arc, but until the value of the current attains a certain magnitude, which depends only on the length of the arc with a given pair of carbons, this change is one of degree merely, and not of character. A greater current simply produces a larger crater, a larger arc, and longer points to the carbons. When the special current is reached, however, a change, which is no longer simply one of degree, takes place in that white-hot depression at the end of the positive carbon from which must of the light of the arc is derived-the crater, as it is called. Instead of presenting a uniformly bright surface to the eye, this becomes partly covered with what appear to be alternately bright and dark lands, sometimes radial like the spokes of a wheel, sometimes in one or more sets of concentric circles, sometimes oscillating, sometimes rotating round different centres in opposite directions. The directions of rotation or oscillation and whole positions of the images change continually, and the motion grows faster and faster as the current is increased.

When the current is so much increased that the motion becomes too fast for the eye to detect, the arc begins to hum, and then, as Mr. Trotter (Proc. Roy. Soc., vol. lvi. p. 262) first showed in 1894, it rotates at the rate of from 50 to $45^{\circ}$ revolutions per second.

As soon as hissing begins the whole appearance of the crater changes again; a sort of cloud seems to draw in round a part of it, moving from the outer edge inwards, and varying continually in shape and position. Sometimes but one bright spot is left, sometimes several, but always the surface is divided into bright and dull parts, giving it a mottled appearance, as is slightly indicated in (b) Fig. 4. If, then, the current be diminished, so that the arc becomes silent again, the whole 
surface of the crater grows dark for an instant, then brightens in spots, and finally becomes bright again all over.

The vaporous arc itself undergoes fewer modifications; it preserves the ordinary characteristics of the silent arc while rotating wheels hold possession of the crater, but, when humming begins, a green light is seen to issue from the crater, and with hissing this becomes enlarged and intensified, till the whole centre of the purple core is occupied by a brilliant greenish-blue light, as is indicated in Fig. 5 .
ILENT.

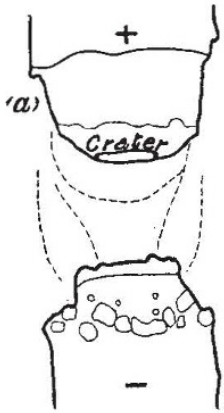

HISSING.

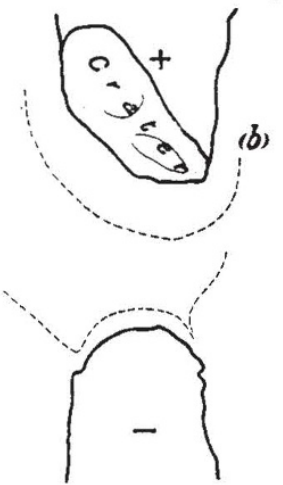

Fig 4-Curbons:-Positive, $9 \mathrm{~mm}$ Cored; Negative, $8 \mathrm{~mm}$ Solid Length of Arc. (a) $5 \mathrm{~mm}$., (b) $8 \mathrm{~mm}$. Current $(a) 3.5$ amperes, (b) 34 amperes.

M. Blondel, whose accuracy of observation and originality in experiment have added so much to our knowledge of the arc, first mentioned a very curious fact about this vapour in 1893 (The Electrician, I893, vol. xxxii. p. 170). He noticed that, while the arc was silent, the vapour was quite transpurent, so that, when viewed at a proper angle, the crater could be seen through it perfectly; but that, as soon as hissing beg in, the vapour became so op sque as to completely hide the crater.
In any case, however, M. Blondel's theory of a change from vapour to solid particles in the arc when hissing begins seems to me to be hardly tenable, if only for the following reason. Whenever we put solid carbon into the arc, such, for instance, as a very thin carbon rod, it glows far more brilliantly than the surrounding vapour, and hence increases the luminosity of the arc. If, there-

HISSING.

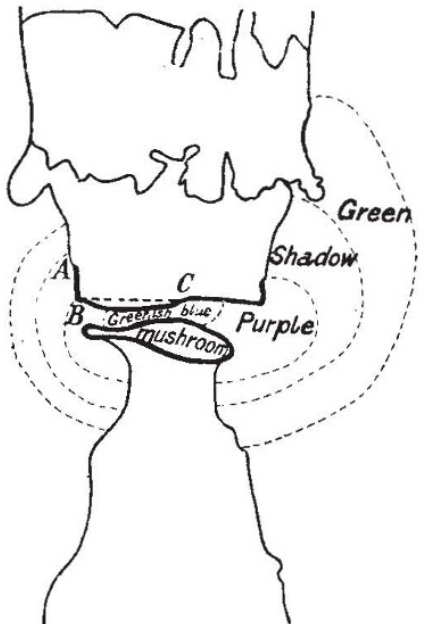

Fig. 5 -Carbons :-Positive, 1 I mm. Solid; Negative, 9 mm. Solid. Length of Arc, I.5 mm. Current, $28^{\circ} 5$ amperes.

fore, hissing is accompanied by a substitution of solid particles for the vapour of the arc, the luminosity of the arc should increase with hissing. But, M. Blondel mentions, in the same article, that the intrinsic brilliancy of the arc diminishes when hissiang begins, hence the theory of a disruptive discharge of solid particles does not appear to cover the facts.
SILENT.

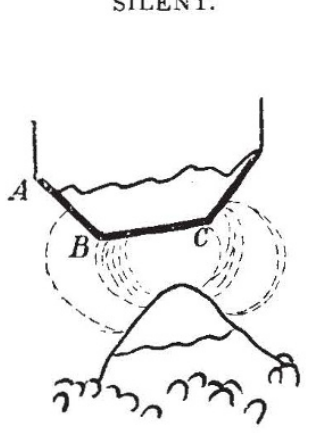

(a)
SILENT.

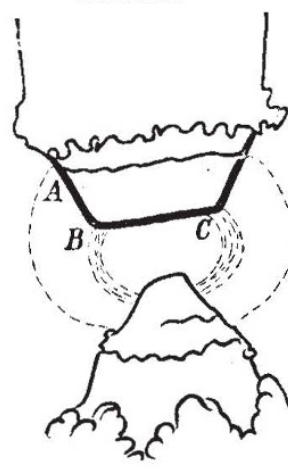

(6)
ON THF

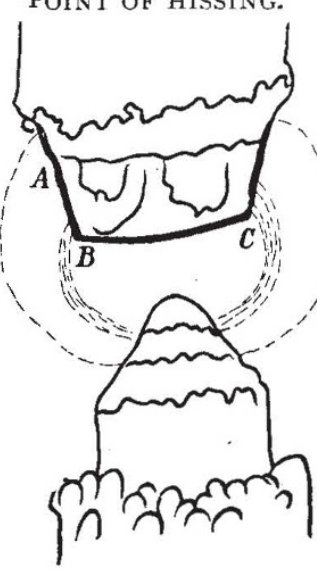

(c)
HISSING.

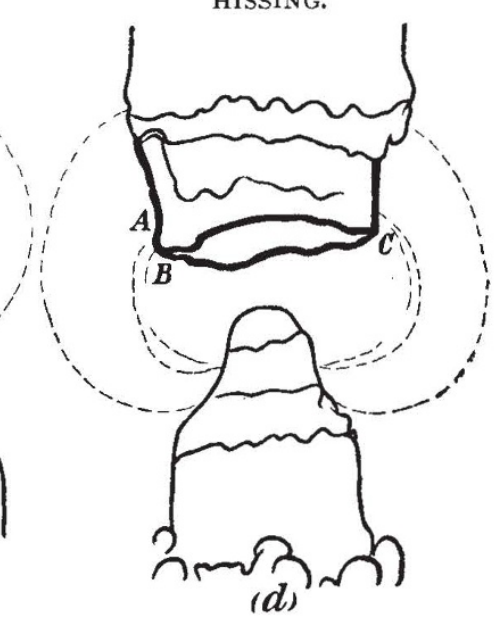

FIG. 6.-Carbons:-Positive, $x \mathrm{~mm}$. Solid; Negative, $9 \mathrm{~mm}$. Solid. Length of Arc, $2 \mathrm{~mm}$. Current, (a) 6 amperes, (b) $x 2$ amperes, (c) 20 amperes, $(d)$ 3o amperes.

M. Blondel believes that, when hissing begins, the gentle evaporation of the carbon of the crater, which feeds the column of vapour in the silent arc, gives place to a disruptive discharge of solid particles torn from the crater.

I have found the opacity of the hissing arc less complete and less invariable than $\mathrm{M}$. Blondel, probably because my conditions were different from his. Indeed I have often been able to see the crater of a hissing arc through the vapour as clearly as if the arc were silent.
The shape of the arc also alters when hissing begins. When the arc is silent its shape is rounded, and it has an appearance of great stability; but as soon as hissing occurs, it seems suddenly to dart out from between the carbons and to become flattened out, as if under the influence of a centrifugal force act. ing at right angles to the common axis of the two carbons. In Fig. 5 and in $(d)$ Fig. 6, this flattened appearance is well marked; and indeed these firures show that every part of the vaporous arc itself is involved in this flattening - the purple core,

NO. I 55 I, VOL. 60] 
the shadow round it, and the green aureole-as if they were all revolving with great rapidity round a common axis. And what more likely than that this should be the case, since, as has already been mentioned, the arc is revolving at the rate of $45^{\circ}$ revolutions per second at the moment that it starts hissing?

As regards the carbons themselves, the only important modification of the negative carbon that appears to be due to hissing is the formation of the well-known "mushroom" at the end of that carbon with a short hissing arc. This mushroom, of which a good example is seen in Fig. 5, is well named, not only because of its shape, but also because of the rapidity of its growth, which is so great that, while it is forming, the carbons often have to be separated, instead of being brought together, to keep the length of the arc constant.

(To be continued.)

\section{HYBRIDISATION.}

UR first duty, and a very pleasant one it is, is to welcome our foreign guests, our friends from across the sea, as I prefe to call them, to thank them for their presence here to-day, and to express a hope that their sojourn among us may be both agreeable and profitable. At the same time we regret that some, such as Dr. Focke, the historian of hybridisation, has not been able to preside over this meeting, as we had hoped he might have done. Nor can we at such a meeting do other than express our abiding regret at the loss, though at an advanced age, of the great hybridiser Charles Naudin.

Our next duty is to thank the Council of the Royal Horticultural Society for this opportunity of meeting once more in these time-honoured gardens to discuss what I venture to think is one of the, if not the most, important subject in modern progressive experimental horticulture. I use the words progressive and experimental because I believe that the future of horticulture depends very greatly on well-directed experiment.

So far as the details of practical cultivation are concerned, we are not so much in advance of our forefathers. We have infinitely greater advantages, and we have made use of them, but if they had had them they would have done the same. We are able to bring to bear on our art not only the "resources of civilisation " to a degree impossible to our predecessors, but we can avail ourselves also of the teachings of science, and endeavour to apply them for the benefit of practical gardening. We are mere infants in this matter at present, and we can only dimly perceive the enormous strides that gardening will make when more fully guided and directed by scientific investigations. One object of this conference is to show that cultural excellence by itself will not secure progress, and to forward this progress by discussing the subject of cross-breeding and hybridisation in all their degrees, alike in their practical and in their scientific aspects.

To appreciate the importance of cross-breeding and hybridisation we have only to look round our gardens and our exhibition-tents, or to scan the catalogues of our nurserymen. Selection has done and is doing much for the improvement of our plants, but it is cross-breeding which has furnished us with the materials for selection.

A few years ago by the expression "new plants" we meant plants newly introduced from other countries, but, with the possible exception of orchids, the number of new plants of this description is now relatively few.

The "new plants" of the present day, like the roses, the chrysanthemums, the fuchsias, and so many others, are the products of the gardeners' skill. From peaches to potatoes, from peas to plums, from strawberries to savoys, the work of the cross-breeder is seen improving the quality and the quantity of our products, adapting them to different climates and con. ditions, hastening their production in spring, prolonging their duration in autumn. ${ }^{2}$ Surely in these matters we have outdistanced our ancestors.

But let us not forget that they showed us the way. I do not

${ }^{1}$ Substance of the address by Dr. Maxwell T. Masters, F.R.S., delivered on opening the proceedings of the International Conference on "Hybridis. ation," Tuesday, July $\mathrm{x}$.

2 See some interesting observations of MacFarlane on the period of 2 See some interesting observations of MacFarlane on the period of
flowering in hybrids as intermediate between that of the parents, Gardeners' Chronicle, June 20, 1891; and on the structure of hybrids, May 3,1890.

NO. I 55 I, VOL. 60$]$ propose to dilate on the share which Camerarius, Millington, Grew, Morland, and others, at the close of the seventeenth century had in definitely establishing the fact of sexuality in plants, but I do wish to emphasise the fact that it was by experiment, not by speculation, nor even by observation, that the fact was proved, and I do wish to show that our English gardeners and experimenters were even at that time quite aware of the importance of their discovery, and forestalled our Herbert and Darwin in the inferences they drew from it. In proof of which allow me to quote from a work of Richard Bradley, called "New Improvements of Planting and Gardening, both Philosophical and Practical," published in 1717 , cap. ii. After alluding to the discovery of the method of the fertilisation of plants, he says (p. 22):-

"By this knowledge we may alter the property and taste of any Fruit by impregnating the one with the Farina of another of the same class; as, for example, a Codlin with a Pearmain, which will occasion the Codlin so impregnated to last a longer time than usual, and be of a sharper taste; or if the Winter Fruits should be fecundated with the Dust of the Summer kinds, they will decay before their usual Time; and it is from this accidental coupling of the Farina of one with the other, that in an Orchard where there is Variety of Apples, even the Fruit are gathered from the same Tree differ in their Flavour and Times of ripening; and, moreover, the Seeds of those Apples so generated, being changed by that Means from their Natural Qualities, will produce different kinds of Fruit if they are sown.

"'Tis from this accidental coupling that proceeds the numberless varieties of Fruits and Flowers which are raised every day from Seed. . .

"Moreover, a curious Person may by this knowledge produce such rare kinds of Plants as have not yet been heard of, by making choice of two Plants for his Purpose, as are near alike in their Parts, but chiefly in their Flowers or Seed vessels; for example, the Carnation and Sweet William are in some respects alike, the Farina of the one will impregnate the other, and the Seed so enlivened will produce a Plant differing from either, as may now be seen in the garden of Mr. Thomas Fairchild, of Hoxton, a plant neither Szeet William nor Carnation, but resembling both equally, which was raised from the seed of a Carnation that had been impregnated by the Farina of the Sweet William."

Here we have the first record of an artificially-produced hybrid, and you will remark that this was more than forty years before Kolreuter began his elaborate series of experiments. Fairchild was the friend and associate of Philip Miller, and of a small knot of advanced thinkers and workers who banded themselves together into a "Society of Gardeners."

"He is mentioned," says Johnson in his " History of English Gardening," "throughout Bradley's works as a man of general information, and fond of scientific research, and in them are given many of his experiments to demonstrate the sexuality of plants, and their possession of a circulatory system. He was a commercial gardener at Hoxton, carrying on one of the largest trades as a nurseryman and florist that were then estab. lished. He was one of the largest English cultivators of a vineyard, of which he had one at Hoxton as late as 1722. He died in 1729 , leaving funds for insuring the delivery of a sermon annually in the church of St. Leonard's, Shoreditch, on Whit Tuesday, 'On the wonderful works of God in the Creation; or On the certainty of the resurrection of the dead, proved by the certain changes of the animal and vegetable parts of the creation." "

Fairchild was thus not only the raiser of the first garden hybrid, but the originator of the flower services now popular in our churches.

We do not hear much of intentionally-raised hybrids from this time till that of Linnæus, in I759 ("Amœn. Acad.," ed. Gilibert, vol. i. p. 212). The great Swedish naturalist, having observed in his garden a Tragopogon, apparently a hybrid between $T$. pratensis and $T$.parvifolius, set to work to ascertain whether this conjecture was correct. He placed pollen of $T$. parvifolius on to the stigmas of $T$. pratensis, obtained seed, and from this seed the hybrid was produced.

About the same time (that is, in I760) Kolreuter began his elaborate experiments, but these were made with no practical aim, and thus for a time suffered unmerited oblivion.

Some years after, the President of this Society, Thomas. 